\title{
Barriers to Providing Health Education During Primary Care Visits at Community Health Centers: Clinical Staff Insights
}

Jessica Alicea-Planas

Fairfield University, jplanas@fairfield.edu

Alix Pose

Linda Smith

Follow this and additional works at: https://digitalcommons.fairfield.edu/nursing-facultypubs Copyright 2015 Springer. Post print archived here with permission. The final publication is available at Springer via http://dx.doi.org/10.1007/s10900-015-0085.2

\section{Peer Reviewed}

\section{Repository Citation}

Alicea-Planas, Jessica; Pose, Alix; and Smith, Linda, "Barriers to Providing Health Education During Primary Care Visits at Community Health Centers: Clinical Staff Insights" (2015). Nursing and Health Studies Faculty Publications. 63.

https://digitalcommons.fairfield.edu/nursing-facultypubs/63

\section{Published Citation}

Alicea-Planas, Jessica, Alix Pose, and Linda Smith. "Barriers to Providing Health Education During Primary Care Visits at Community Health Centers: Clinical Staff Insights." Journal of community health (2015): 1-6. doi:10.1007/ s10900-015-0085.2

This item has been accepted for inclusion in DigitalCommons@Fairfield by an authorized administrator of DigitalCommons@Fairfield. It is brought to you by DigitalCommons@Fairfield with permission from the rightsholder(s) and is protected by copyright and/or related rights. You are free to use this item in any way that is permitted by the copyright and related rights legislation that applies to your use. For other uses, you need to obtain permission from the rights-holder(s) directly, unless additional rights are indicated by a Creative Commons license in the record and/or on the work itself. For more information, please contact digitalcommons@fairfield.edu. 
RUNNING HEAD: Barriers to health education during primary care

Barriers to providing health education during primary care visits at community health centers: Clinical staff insights

Jessica Alicea-Planas, PhD, RN, MS, MPH, CHES, Assistant Professor, School of Nursing Fairfield University- 1073 North Benson Road, Fairfield, CT 06824 / (203) 254-4000 ext. 2738 jplanas@ fairfield.edu (Corresponding Author)

Alix Pose, MD, MPH, Director of Quality Improvement Optimus Healthcare, Inc. 982 East Main Street, Bridgeport, CT. 06608/ (203) 696-3260 apose@opthc.org

Linda Smith, MPH, Director of School Based Health Centers and Wellness Programs Optimus Healthcare, Inc. 982 East Main Street, Bridgeport, CT. 06608/ (203) 696-3260 lsmith@opthc.org

The authors would like to acknowledge the support of Sigma Theta Tau International, Mu Chi chapter. 


\begin{abstract}
:
The rapid increase of diverse patients living in the U.S. has created a different set of needs in healthcare, with the persistence of health disparities continuing to challenge the current system. Chronic disease management has been discussed as a way to improve health outcomes, with quality patient education being a key component. Using a community based participatory research (CBPR) framework, this study utilized a web-based survey and explored clinical staff perceptions of barriers to providing patient education during primary care visits. With a response rate of nearly $42 \%$, appointment time allotment seemed to be one of the most critical factors related to the delivery of health education and should be considered key. The importance of team-based care and staff training were also significant. Various suggestions were made in order to improve the delivery of quality patient education at community health centers located in underserved areas.
\end{abstract}

Key words: Health education, community health centers, health disparities, clinical staff perceptions 


\section{Background}

The cultural landscape in the United States of America has dramatically changed in the last few decades. Particularly in healthcare, the rapid increase of diverse patients has created a different set of needs and demands on providers and organizations, with the persistence of health disparities continuing to challenge the current systems. Elimination of these health inequalities has become a national priority since they have contributed to poorer health outcomes, which include an increase in chronic disease, disability and premature death for racial/ethnic minorities at an alarming rate (Center for Disease Prevention and Control, 2011). Providing patients with appropriate health education during primary care visits has been shown to improve self-efficacy in chronic disease management (Weiler \& Tirrell, 2007; Parra-Medina, Wilcox, Salinas et al., 2011), which is essential to achieving a state of quality health (Huber, Knottnerous, Green, et al., 2011). Understanding some of the challenges faced when providing patient education to a culturally diverse population from a clinical staff perspective, may assist in improving future health outcomes for vulnerable populations.

Chronic disease \& health disparities. Almost half of all Americans adults, over the age of 18 , live with a chronic disease and one in four adults have two or more (Ward, Schiller \& Goodman, 2014). Chronic diseases are currently the leading causes of death and disability in the United States, with $86 \%$ of all health care spending in 2010 being consumed by people with one or more chronic conditions (Gerteis, Izreal, Deitz, et al., 2014). For certain vulnerable populations like Blacks, Asians, and Hispanics, areas where health disparities are worsening involve preventive services and management of chronic conditions. These vulnerable populations are also more likely to be diagnosed and/or self-managing chronic conditions that cost our healthcare system billions of dollars a year. 
Access to healthcare is affected by both financial and non-financial barriers that often overlap and can delay care and can compound the problem of health disparities (Kullgren \& McLaughlin, 2010). There are also certain institutional barriers that contribute to the growing problem of persistent health inequality. Our current healthcare system demonstrates many deficiencies in managing chronic conditions which include: rushed practitioners not following established guidelines, lack of care coordination, lack of follow-up and patients inadequately educated to manage their illness (Group Health Resource Institute, 2010). The shortage of bilingual-bicultural healthcare professionals (Institute of Medicine (IOM), 2003) and time constraints during patient visits (Anderson \& Ofayiwola, 2012; Chen, Farwell \& Jha, 2009) can also create obstacles to providing equal care to vulnerable populations. There also continues to be suboptimal access to quality health services and medical information, especially among lowincome populations within the United States (Agency for Healthcare Research and Quality (AHRQ), 2014). Studies have indicated that only a small percentage of primary care patients receive appropriate health education counseling (Ritsema, Bingenheimer, Scholting \& Cawley, 2014; Hing, Hooker \& Ashman, 2011). Of particular importance within the scope of chronic care, are the resources available to patients to assist in the management of their disease(s), with health education being a key component.

\section{Methods}

This study employed a non-experimental, exploratory research design and involved a convenience sample of healthcare professionals employed at a large federally qualified health center [FQHC] located in an inner-city urban area of southwestern Connecticut. An FQHC is dedicated to meeting the needs of medically disadvantaged populations and is usually located in an underserved area. National data demonstrates that a majority of their patients are low income, 
with $72 \%$ of health center patients having family incomes at or below poverty. Roughly $36 \%$ of health center patients are uninsured and another $40 \%$ survive on Medicaid as a primary means of health insurance (National Association of Community Health Centers [NACHC], 2014). Any non-clinical staff members were excluded from the study. A web-based survey was utilized as a means to assess current clinical staff practices as they relate to the provision of health education, and organizational influences on resource availability.

Following university Institutional Review Board approval, initial data collection began using a community based participatory research (CBPR) framework (AHRQ, 2003). This is a collaborative approach that would enable the staff to more actively participate in the research process, with the goal of influencing a sustainable change and ultimately the quality of health education being provided to the priority population. Input from the staff (nurses and providers) involved in direct patient care was recognized as imperative prior to planning any type of intervention to address the health education needs of the patients.

Due to the lack of published instruments related to assessing barriers for providing effective health education, a survey was developed for this study. Prior to creating the survey multiple emails were sent out to the clinical staff requesting their expertise and input regarding the health education they currently provided. The researcher also met with various groups of staff during multiple nursing and clinical meetings (five in total) to try to gain additional knowledge related to organizational processes and system structure. The information received from both the meetings and emails was then used to inform the creation of the web-based survey. Multiple drafts of the survey were reviewed by key stakeholders within the organization before the final iteration of the survey was achieved. Questions were added and changed based on the input received from the community partner. The survey explored not only individual factors, but 
also system influences on clinical staffs' ability to perform the necessary tasks and specifically targeted what support systems or resources were needed in order to make future improvements to patient education. Both open and closed ended questions were used in the survey. There were no prior reliability or validity statistics available, as the instrument was created specific for the needs of this population and organization.

A link to the online survey was sent out to all clinical staff, along with a small paragraph explaining the purpose of the study. Considering the minimal risk to participants, a consent paragraph was utilized prior to the start of the online survey. The online link was live for one month and a total of three reminder emails were sent out to potential participants. The link to the survey was also posted on the organizations internal website (although usage data demonstrated that only one person accessed the survey via this link). Participants were provided with the option of being included in a drawing for one of eight $25 \$$ Dunkin Donuts gift cards upon completion of the survey.

\section{Data Analysis}

Out of 375 potential participants, a total of 153 responded to the online survey (response rate of $41.8 \%$ ). However, complete data were only available on 74. Quantitative data were analyzed using SPSS v. 21 and qualitative data were summarized without using any formal statistical analysis. Table 1 represents a descriptive analysis of the categorical variables in the current study. The sample was majority female (93\%) with the largest percentage of participants having worked at this community health center between 1-5 years (41.9\%). Those who responded self-identified as ethnically diverse (55\% Latino/Hispanic, 21\% Caucasian, 7\% African American/Black, 3\% Asian/Pacific Islander). This community health center has a total of 16 delivery sites and representation was obtained from 10 of the sites. The survey targeted 
clinical staff only, and the largest number of respondents were Medical Assistants (31.5\%), followed by nursing staff (27.0\%) and then providers (25.9\%). Other roles of respondents included those from the dental and social work department.

The majority of respondents $(77.8 \%)$ felt that all clinical staff should be responsible for providing health education to patients and did not see it as the sole role of one individual (i.e. nurses only or the doctor's job). Nearly $80 \%$ of clinical staff felt that there was not enough time allotted during the patient visit for health education. More than half of respondents $(51 \%)$ reported spending between one to five minutes per patient encounter on education. Only $25 \%$ devoted between six to ten minutes to education and $17 \%$ used greater than ten minutes. Chisquared analysis revealed that none of these variables were significantly influenced by clinical staff role, age or length of employment.

Qualitative responses demonstrated that a longer patient visit was overwhelmingly cited as a process /operational change that could improve patient outcomes. Scheduling, reorganization of nurse responsibilities and staffing were also described as areas needing enhancement so that more time can be included for patient education. One participant noted: "streamline registration and screening to essentials so that more time is available [for patient education] during patient appointment time". Another stated "fifteen minute visits are just not enough with our population of patients".

Chi-square analysis indicated that being a provider was associated with a higher percentage who felt that additional training for staff would be useful in providing more effective health education, $X(2)=7.47, p<.05$. Specifically, $76.3 \%(\mathrm{n}=45)$ of providers reported yes (to additional training for staff) versus $23.7 \%(n=14)$ of nurses. Despite the availability of bilingual staff and other resources (like the language line), $49 \%$ of respondents described language as a 
barrier to providing effective patient education. Only $39 \%$ reported that electronic health records help to make patient education more efficient. And while there are currently embedded links available in the electronic health record to assist with access to patient education, $80 \%$ of the respondents were not aware of them. A majority of clinical staff $(81 \%)$ also felt that hiring additional healthcare workers would help in the delivery of health education, and cited hiring additional licensed nursing staff and nutritionists as key to the process.

Roughly half of respondents (51\%) felt that the handout materials currently available were not sufficient to meet the patient needs. Those supplemented their response $(n=56)$ included that the current information needed to be updated. They also sought a more varied selection (including language and alternate topics) and resources need to be on-hand and ready to give to patients. This would allow for less searching on the part of the clinical staff and more time for patient education.

Open ended questions were used in order to garner concrete examples of ways to improve patient education. Out of 110 responses, 55 suggested scheduling (or more time allotted for each patient visit) be considered as a way for more patient education to be incorporated into the visit. Other suggestions included using group visits as a way to provide education, assigning dedicated staff (mostly discussed as a nurse role) to provide the education and ensuring resource availability (described as handouts, DVDs, staff trainings). Staff recognized the importance of identifying patient needs, using the correct delivery method based on learning needs of the patient and the need for staff to be trained. They also expressed a desire for the electronic health record to be used more efficiently as a way to document the education being provided.

Being that this health center provides care across the lifespan and also includes various specialty services, there were a wide range of answers reporting type of additional trainings that 
would be useful (see Figure 1). Twenty seven percent of respondents were also willing to try to use text messages in order to improve the delivery of health education. Chi-square analysis indicated a significant association between willingness to use text messages and role responsibility. A higher percentage of those who felt health education was the responsibility of multiple staff members were more willing to try to use text messaging for health education, $X$ (2) $=5.86, p<.05$, with a small to medium effect size $(\mathrm{Phi}=.23)$.

\section{Limitations}

Participants may have based their responses on personal experiences that may or may not be representative of the entire clinical staff community. Self-reporting on the survey should be considered a limitation. Since all participants were from one large community health center, results may not be generalizable to other populations, but the representation from various sites throughout multiple cities is noteworthy. Since the term "patient education" was not defined in the survey, the lack of a standardized definition among respondents is an important limitation. Given the broad range of items that may fall into this category, the researchers did not feel it was necessary to include but some may consider this a shortcoming.

There were a large number of participants that did not answer various demographic questions. One could think it was in fear of being identified based on their responses or perhaps the relevance of that information was not understood by the staff. Not including demographic data (especially role and site information) was considered during the survey creation, however decided against, with hopes of discovering nuances within the data.

\section{Discussion}

The delivery of appropriate and consistent health education in order to decrease health disparities was identified by this community partner as a priority. There is limited research 
available on clinical staff's perception of barriers to providing appropriate health education. Community health centers $(\mathrm{CHC})$ disproportionately serve more patients with diabetes, hypertension, depression and asthma when compared with other primary care physicians (NACHC, 2014).Yet despite this, research has confirmed that these service delivery sites can be successful in reducing racial/ethnic health disparities, especially when compared to disparities found nationwide (Lebrun, Shi, Zhu, et al., 2013; Shi, Lebrun-Harris, Daly, et al., 2013).

In this current study appointment time allotment seemed to be one of the most important factors related to the delivery of health education and should be considered key. Primary care visits during which physicians provide appropriate counseling or screening, take longer than visits in which they do not (Chen, Farwell \& Jha, 2009). While there were various suggestions made on ways to increase the availability of time, the primary recommendation was extended patient visits. From a system perspective, staff perceived administration's willingness to make adjustments as minimal. Some of these comments included; "administrators and all staff would need to understand the importance of it [health education]" and "they have to stop just looking at productivity". As healthcare costs continue to rise and CHCs contend with funding issues, better communication between administration and staff may open dialogue to discuss extended patient visits as an option for certain complex patients.

Organizations may have to utilize more creative ways to deliver health education if extending appointment visit time is not an option. Suggestions made by clinical staff included: "have monthly seminars and invite patients who are interested"; "educational DVDs can be played in the waiting rooms", "use group visits as an option"; "set up visits just for education"; "monthly themes on wellness and prevention" and "need more handouts and pamphlets that are geared towards our patient's level of education... more visual aids would be extremely helpful". 
The use of technology to deliver health education to culturally diverse patients is also promising; especially since those who seek health information on the internet (and other media sources) continues to grow (Hing, Hooker \& Ashman, 2009). A more cost effective option for resource limited organizations may be to utilize their current electronic health record at a greater capacity. A number of respondents seemed open and willing to pursue this alternative; "having more resources available in the EHR [electronic health record] education tab would be helpful and make the process more efficient". Ensuring that staff are aware of what is currently available to use (i.e embedded links within the electronic health record) may also improve the ability of staff to access educational literature.

The significant association between willingness to use text messages and role responsibility is also worth note. Those who felt health education was the responsibility of multiple staff members were more willing to try to use text messaging for health education. Encouraging team work, communication and joint responsibility for patient centered care between staff members may increase their willingness to attempt alternate means of health education delivery.

The Committee for Unequal Treatment suggested increasing the knowledge base of healthcare providers on causes and interventions to reduce health disparities (IOM, 2003). For examples, diabetes education training for office nurses working at a community health center demonstrated statistically significant results in patient HgbA1C results (Weiler \& Tirrell, 2007). Similarly, additional training of current staff may be a viable option to improve the quality of health education delivered to patients. As one respondent commented, "when the staff is educated and instructed [on what to do] they are more comfortable with educating the patient". Improving available resources and information should supplement patient teaching. 
Although at times challenging to work in underserved areas, CHC's have demonstrated that they are a viable option for providing primary care for many vulnerable populations. In order to decrease health disparities, our healthcare system requires quality patient education with the aim of improved chronic disease management. Understanding the perceived barriers from those who work directly with these priority populations, can create a more team based approach to patient-centered care. Utilizing a CBPR framework to engage key players (healthcare providers) of community health centers, will hopefully influence continued enthusiasm for modifications in system, program or organizational policies. Future interventions to improve the delivery of health education will help establish best practices for chronic disease management among priority populations. 


\section{References}

Agency for Healthcare Research and Quality (2014, October). Disparities in Healthcare Quality Among Racial and Ethnic Minority Groups: Selected Findings from the 2010 National Healthcare Quality and Disparities Reports. Rockville, MD. Retrieved from http://archive.ahrq.gov/research/findings/nhqrdr/nhqrdr10/minority.html

Agency for Healthcare and Quality. (2003 June). The Role of Community-Based Participatory Research: Creating Partnerships, Improving Health. AHRQ Publication No. 03-0037, Rockville, MD. Retrieved from http://www.ahrq.gov/research/cbprrole.htm

Anderson, D. R. \& Ofayiwola, J. N. (2012). Community health centers and the patient-centered medical homes: challenges and opportunities to reduce health care disparities in America. Journal of Health Care for the Poor and Underserved, 23(3), 949-57. doi: 10.1353/hpu.2012.0099.

Centers for Disease Control and Prevention. (2011, January 11). CDC Health Disparities and Inequalities Report - United States, 2011. Morbidity and Mortality Weekly Review, 60 (Supplement): 1-114. Retrieved from http://www.cdc.gov/mmwr/pdf/other/su6001.pdf

Chen, L. M., Farwell, W. R., \& Jha, A. K. (2009). Primary care visist duration and quality- Does good care take longer? Archives of Internal Medicine, 169 (20), 1866-1872. doi: 10.1001/archinternmed.2009.341.

Gerteis, J., Izrael, D., Deitz, D., LeRoy, L., Ricciardi, R., Miller, T. \& Basu, J. (2014, April). Multiple Chronic Conditions Chartbook. AHRQ Publications No, Q14-0038. Rockville, MD. Retrieved from http://www.ahrq.gov/professionals/prevention-chroniccare/decision/mcc/mccchartbook.pdf 
Group Health Research Institute (2010). Improving chronic illness care. Retrieved from http://www.improvingchroniccare.org/index.php?p=The_Chronic_Care_Model\&s

Hing, E., Hooker, R. S., \& Ashman. (2011). Primary health care in community health centers and comparison with office-based practices. Journal of Community Health, 36, 406-413. doi: $10.1007 / \mathrm{s} 10900-010-9322-\mathrm{x}$

Huber, M., Knottnerous, J. A., Green, L., van der Horst, H., Leonard, B., Lorig, K...Smid, H. (2011). How we should define health? BMJ, 343. doi: http://dx.doi.org/10.1136/bmj.d4163

Institute of Medicine. (2003). Unequal treatment: confronting racial and ethnic disparities in health care. Retrieved from http://www.nap.edu/openbook.php?isbn=030908265X

Kullgren, J. T. \& McLaughlin, C. G. (2010). Beyond affordability: The impact of nonfinancial barriers on access for uninsured adults in three diverse communities. Journal of Community Health, 35, 240-248. doi: 10.1007/s10900-010-9230-0

Lebrun, L. A., Shi, L., Zhu, J., Sharma, R., Sripipatana, A., Hayashi, S., \& Daly, C. A. (2013). Racial/Ethnic differences in clinical quality performance among health centers. Journal of Ambulatory Care Management, 36 (1), 24-34. Retrieved from http://bphc.hrsa.gov/publications/racialdifferences.pdf

National Association of Community Health Centers. (2014). A sketch of community health centers. Retrieved from http://www.nachc.com/client//Chartbook_December_2014.pdf

Parra-Medina, D., Wilcox, S., Salinas, J., Addy, C., Fore, E., Poston, M. \& Wilson, D. K. (2011). Results of a heart healthy and ethnically relevant lifestyle trial: A cardiovascular risk reduction intervention for African American woman attending community health centers. American Journal of Public Health, 101(10), 1914-1921. doi:

10.2105/AJPH.2011.300151 
Ritsema, T. S., Bingenheimer, J. B., Scholting, P., \& Cawley, J. F. (2014). Differences in the delivery of health education to patients with chronic disease by provider type, 2005-2009. Preventing Chronic Disease, 11, 130-175. doi: http://dx.doi.org/10.5888/pcd11.130175

Shi, L., Lebrun-Harris, L.A., Daly, C.A., Sharma, R., Sripipatana, A., Hayashi, A.S., \& NgoMetzger, Q. (2013). Reducing disparities in access to primary care and patient satisfaction with care: The role of health centers. Journal of Health Care for the Poor and Underserved, 24 (1), 56-66. doi: 10.1353/hpu.2013.0022.

Ward, B. W., Schiller, J. S. \& Goodman, R. A. (2014). Multiple chronic conditions among US adults: a 2012 update. Preventing Chronic Disease, 11, 1-4. doi: http://dx.doi.org/10.5888/pcd11.130389.

Weiler, D. M. \& Tirrell, L. (2007). Office nurse educators: Improving diabetes self-management for the Latino population in the clinic setting. Hispanic Health Care International, 5 (1), 21-26. 